\title{
Adverse Drug Reaction due to Cancer Chemotherapy and its Financial Burden in Different Hospitals of Nepal
}

\author{
Sunil Shrestha $^{1 *}$, Rajani Shakya ${ }^{2}$, Sudip Shrestha ${ }^{3}$ and Sachin Shakya ${ }^{3}$ \\ ${ }^{1}$ Lecturer of Pharmacology and Toxicology, Nobel College, Kathmandu \\ ${ }^{2}$ Department of Pharmacy, Kathmandu University, Dhulikhel
}

${ }^{3}$ Department of Oncology, Nepal Cancer Hospital \& Research Center, Harisidhhi, Nepal

Received: February 27, 2017; Accepted: March 24, 2017; Published: April 18, 2017

*Corresponding author: Sunil Shrestha, Lecturer of Pharmacology and Toxicology, Nobel College, Kathmandu, E-mail: HYPERLINK"mailto:sunilcresta@ gmail.com"sunilcresta@gmail.com

\section{Abstract}

Adverse Drug Reactions (ADRs) are inevitable risk factors associated with cancer chemotherapy. A great emphasis is needed for their detection, assessment, monitoring, reporting and prevention.

A prospective cohort study was carried out at oncological ward of three different hospitals in Kathmandu, Nepal with objectives to study the pattern of ADRs; and to assess the causality, severity and preventability using different types of scales like Naranjo Algorithm, modified Hartwig and Siegel and modified Shumock and Thornton scale.

Age greater than 60 years and female gender were found to the risk factors for developing ADRs due to anticancer medications. Alkylating agents were found to be responsible for ADRs in $32.51 \%$ followed by antimetabolites (29.62\%). Carboplatin was responsible for $14.40 \%$ of the ADRs followed by Gemcitabine (13.58 $\%)$ and fluorouracil (13.16\%). Paclitaxel, Docetaxel, Cisplastin and Doxorubicin were found to be other drugs identified for causing ADRs. Anemia (42.6 \%) was the most commonly encountered ADR followed by fever and neutropenia. ADRs of the suspected drug was found be continuing in $36.9 \%$. Chemotherapy was stopped in $21.3 \%$, discontinued and drug changed in $27.86 \%$, dose reduced in $13.9 \%$ and drug changed in $11.5 \%$. Most of the reactions were probable (66\%) in causality, moderate $(72.4 \%)$ in severity and probably preventable $(52.2 \%)$ in nature. ADRs increased cost of illness due to added therapy for management of ADRS, additional clinical investigations and prolongation of hospital stay.

ADRs are still of a great problem in cancer patient care. All involved in management of a cancer patient have to play a great role in detection, monitoring and prevention of ADR to provide the better pharmaceutical care to patients.

Keywords: Adverse drug reactions; Cancer; Chemotherapy; Nepal

\section{Introduction}

Cancer is a multi-cellular disease which can arise from any cell type and organs [1]. It is an outrageous disease which can bring terrible social misery, psychological distress and suffering to the patients and relatives [2]. In Nepal cancer is still believed to be a disease of death though advances in medical science have changed perception towards cancer to certain extent [3]. Some of the types of cancer have been proven to be curable now. Though being effective, cancer chemotherapeutic agents are frequently associated with several Adverse Drug Reactions (ADRs). ADRs of cancer chemotherapy have considerable economic as well as clinical costs as they often lead to hospital admission, prolongation of hospital stay and emergency department visits. ADRS can range from mild nausea, vomiting to fatal myelosuppression. Sometimes the ADRs may be so serious and severe that cost needed to treat morbidity and mortality due to it, is more than the cost needed to treat the actual condition itself $[4,5]$. Despite of being an important issue, proper attention for addressing ADRs of cancer chemotherapy is still lacking. The present study was conducted with an aim to determine the incidence and pattern of cancer chemotherapy induced ADRs. Severity and preventability of ADRs along with their economic burden on patients were also determined.

\section{Materials and Methods}

The study was carried out in the oncology ward of Bhaktapur Cancer Hospital, Om Hospital and Research Centre and Sarvanga Hospital of Nepal. This was the prospective cohort study of six months duration. All in-patients on cancer chemotherapy during the study period were studied and those who developed at least one ADR during treatment were included in the study.

ADR reporting form designed by Centre for Drug Standard Control Organization (CDSCO) was used to collect the data on ADRs. Necessary patient details were collected on a specially designed Performa with the help of clinicians present on site.

Severity and preventability assessments were done as per modified Hartwig and Siegel scale and Modified Shumock and Thorton scale respectively. The causality was assessed using the Naranjo's Causality Assessment Scale. 


\section{Flow chart of the study}

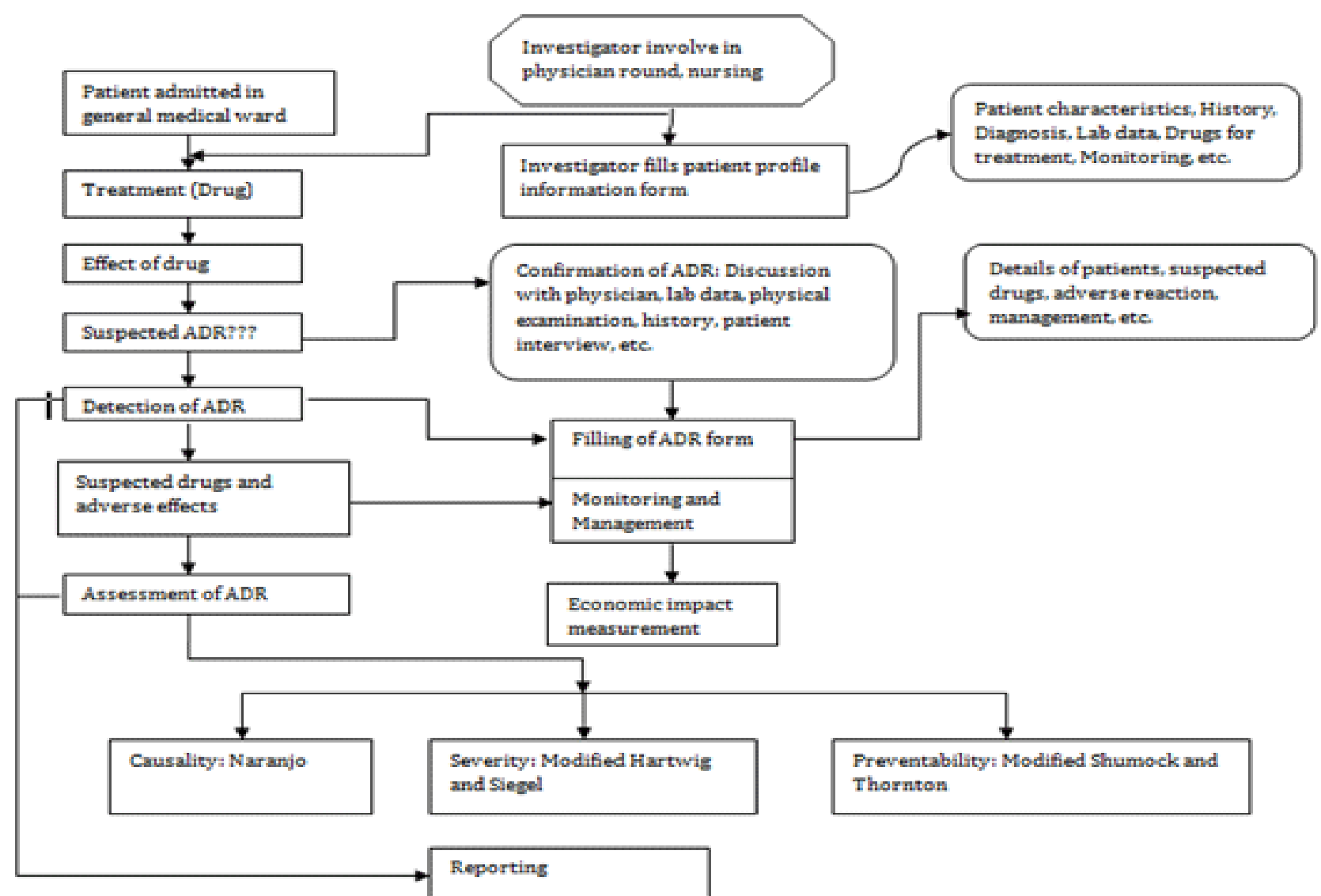

\section{Results}

\section{Flow chart of the study}

\section{Socio-demographic characteristics}

There were 122 patients enrolled who were suffering with ADRSs of cancer chemotherapy. Their demographic and socioeconomic characteristics are shown in Table 1. Patients were between the age group of 16 to 80 years $(54.08 \pm 14.7)$.
Out of the total cases evaluated 49 (40.2\%) were males and 73 $(59.8 \%)$ were females with male-to-female ratio of 1:1.49. Elderly patients (above 60 years of age) encountered majority (41.8\%) of ADRs followed by age group of 41-50 (20.5\%) and 51-60 (18.9\%) years. In this study $71.3 \%$ were literate, $65.6 \%$ were married, $18.0 \%$ were widowed/widower and $13.1 \%$ were unmarried. The majority of cancer patients were farmers $(27.0 \%)$ followed by housewives $(26.2 \%)$. It was found that $44.3 \%$ patients were from low socio-economic status and $42.6 \%$ patients werefrom average socio-economic status. When BMI of patients were calculated, $36.1 \%$ patients were found to be over-weight, $32.0 \%$ were

\begin{tabular}{|c|c|c|c|}
\hline & & Number $(n=122)$ & Percentage (\%) \\
\hline \multirow[t]{2}{*}{ Gender } & Male & 49 & 40.2 \\
\hline & Female & 73 & 59.8 \\
\hline \multirow[t]{6}{*}{ Age group (years) } & Up to 20 & 2 & 1.6 \\
\hline & $21-30$ & 5 & 4.1 \\
\hline & $31-40$ & 16 & 13.1 \\
\hline & $41-50$ & 25 & 20.5 \\
\hline & $51-60$ & 23 & 18.9 \\
\hline & More than 60 & 51 & 41.8 \\
\hline
\end{tabular}




\begin{tabular}{|c|c|c|c|}
\hline \multirow{3}{*}{ Marital Status } & Married & 80 & 65.6 \\
\hline & Unmarried & 16 & 13.1 \\
\hline & Widowed/Widower & 22 & 18.0 \\
\hline \multirow{5}{*}{ Educational Status } & Illiterate & 35 & 28.7 \\
\hline & Below School Leaving Certificate (SLC)* & 23 & 18.9 \\
\hline & School Leaving Certificate (SLC) & 13 & 10.7 \\
\hline & Intermediate & 21 & 17.2 \\
\hline & Graduate or Higher & 30 & 24.6 \\
\hline \multirow{7}{*}{ Occupation } & Farming/Agriculture & 33 & 27.0 \\
\hline & Housewife & 32 & 26.2 \\
\hline & Business & 18 & 14.8 \\
\hline & Officer & 14 & 11.5 \\
\hline & School Teacher & 5 & 4.1 \\
\hline & Engineer & 5 & 4.1 \\
\hline & Doctor & 1 & 0.8 \\
\hline \multirow[t]{3}{*}{ Socio-Economic Status* } & High & 16 & 13.1 \\
\hline & Average & 52 & 42.6 \\
\hline & Low & 54 & 44.3 \\
\hline \multirow[t]{3}{*}{ Smoking Status } & Non-Smoker & 59 & 48.4 \\
\hline & Current Smoker & 44 & 36.1 \\
\hline & Ex-smoker & 19 & 15.6 \\
\hline \multirow{4}{*}{ BMI Status } & Underweight (Below 18.5) & 24 & 19.7 \\
\hline & Normal (18.5 to $\left.24.9 \mathrm{~kg} / \mathrm{m}^{2}\right)$ & 39 & 32.0 \\
\hline & Overweight ( 25.0 to $29.9 \mathrm{~kg} / \mathrm{m}^{2}$ ) & 44 & 36.1 \\
\hline & Obese $\left(30.0 \mathrm{~kg} / \mathrm{m}^{2}\right.$ and above $)$ & 15 & 12.3 \\
\hline
\end{tabular}

underweight and remaining, 19.7\%, had normal body weight. In the study $48.4 \%$ of patients were nonsmoker. Among the remaining, $36.1 \%$ patients were found to have quitted cigarettes few years back whereas remaining $15.6 \%$ were still smoking.

\section{Clinical Diagnosis}

Most of the patients were affected by lung cancer (27.0\%) followed by ovarian cancer $(13.9 \%)$, breast cancer (12.3\%), stomach cancer $(11.5 \%)$ and cervical cancer $(7.4 \%)$.

Gender wise classification of cancer type is shown in Table 2. Lung cancer (20.5\%), stomach cancer $(9.8 \%)$ and rectal cancer $(4.1 \%)$ were the most prevalent cancer types in males whereas in females, ovarian cancer (13.9\%), breast cancer (12.3\%), cervical cancer $(7.4 \%)$ and lung cancer $(6.6 \%)$ were found to be more common.

\section{Chemotherapeutic agents}

Alkylating agents (32.51\%) were found to be responsible for most of the ADRs which was followed by anti-metabolites (29.62\%). Carboplatin was responsible for $14.40 \%$ of the ADRs followed by Gemcitabine (13.58\%) and fluorouracil (13.16\%).

\section{Chemotherapeutic agents}

Alkylating agents (32.51\%) were found to be responsible for most of the ADRs which was followed by anti-metabolites (29.62\%). Carboplatin was responsible for $14.40 \%$ of the ADRs followed by Gemcitabine (13.58\%) and fluorouracil (13.16\%).

\section{ADRs found in cancer patients}

ADRs experienced by the patients based on the organ system are shown in Table 3. Commonly seen ADRs were anemia (42.6\%), fever (39.3\%), neutropenia (31.1\%), muscular weakness (29.5\%) and constipation $(28.7 \%)$.

\section{Hematological disorders}

\section{Chemotherapy induced Anemia}

Out of 122 patients, $52(42.6 \%)$ had developed anemia. Among them, 18.9\% were suffering from Grade II anemia followed by Grade I (14.8\%), Grade III (6.6\%) and Grade IV anemia (2.5\%). 
Table 2: Gender wise distribution of cancer type

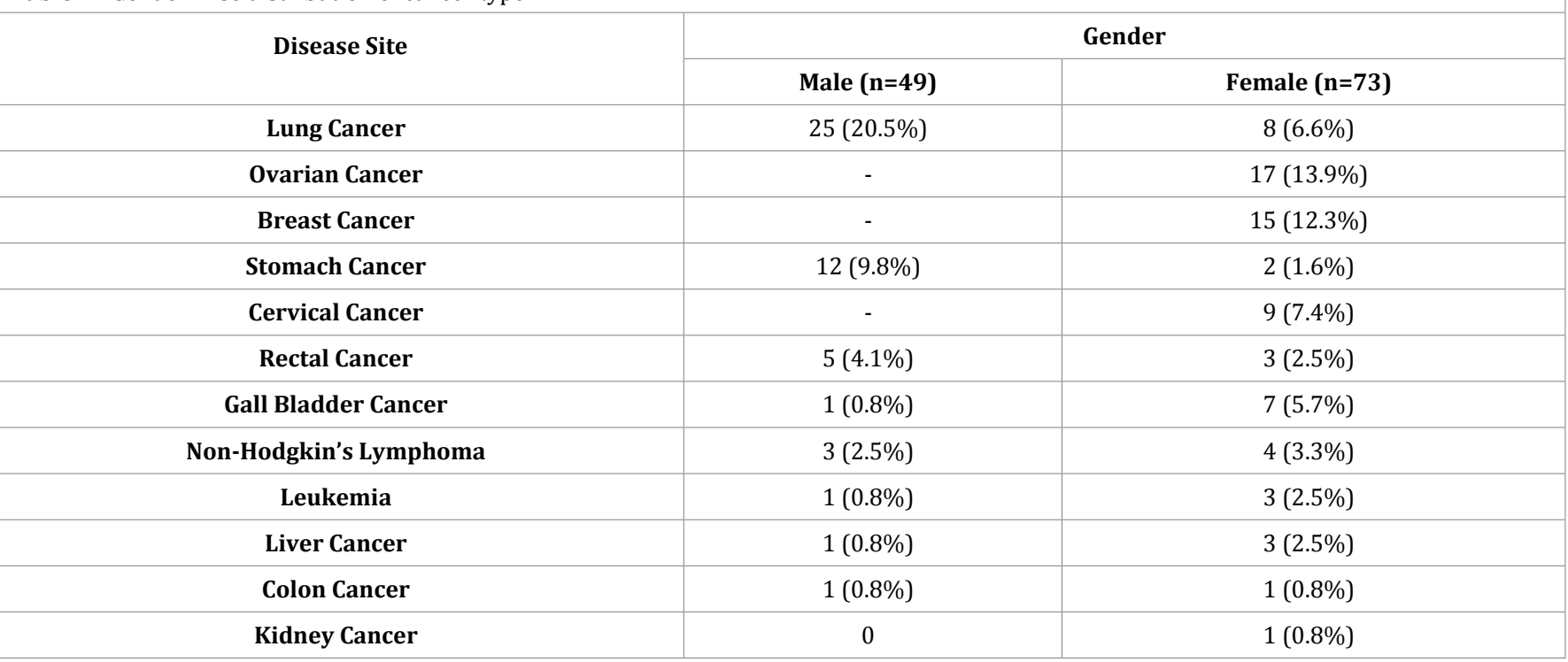

Table 3: ADRs found in cancer patients

\begin{tabular}{|c|c|c|c|c|c|}
\hline Organ System & ADRs & Males(n=49) & Females $(n=73)$ & Total & Percent \\
\hline \multirow{8}{*}{ Gastro-intestinal tract } & Nausea & $13(10.7 \%)$ & $18(14.8 \%)$ & 31 & 25.4 \\
\hline & Vomiting & $9(7.4 \%)$ & $21(17.2 \%)$ & 30 & 24.6 \\
\hline & Diarrhea & $16(13.1 \%)$ & $15(12.3 \%)$ & 31 & 25.4 \\
\hline & Constipation & $11(9.0 \%)$ & $24(19.7 \%)$ & 35 & 28.7 \\
\hline & Abdominal Pain & $10(8.2 \%)$ & $23(18.9 \%)$ & 33 & 27 \\
\hline & Decreased Appetite & $12(9.8 \%)$ & $18(14.8 \%)$ & 30 & 24.6 \\
\hline & Mucositis & $3(2.55 \%)$ & $7(5.7 \%)$ & 10 & 8.2 \\
\hline & Xyrostomia & $4(3.3 \%)$ & $4(3.3 \%)$ & 8 & 6.6 \\
\hline \multirow[t]{2}{*}{ Hematological and lymphatic } & Anemia & $20(16.4 \%)$ & $32(26.2 \%)$ & 52 & 42.6 \\
\hline & Neutropenia & $15(12.3 \%)$ & $23(18.9 \%)$ & 23 & 31.1 \\
\hline \multirow[t]{4}{*}{ Musculoskeletal and nutritional disorders } & Body Aches & $11(9.0 \%)$ & $16(13.1 \%)$ & 27 & 22.1 \\
\hline & Muscle cramps & $2(1.6 \%)$ & $8(6.6 \%)$ & 10 & 8.2 \\
\hline & Muscular weakness & $12(9.8 \%)$ & $24(19.7 \%)$ & 36 & 29.5 \\
\hline & Weight loss & $13(10.7 \%)$ & $17(13.9 \%)$ & 30 & 24.6 \\
\hline \multirow{8}{*}{ Skin and subcutaneous disorders } & Alopecia & $13(10.7 \%)$ & $22(18.0 \%)$ & 35 & 28.7 \\
\hline & Rash & $12(9.8 \%)$ & $11(9.0 \%)$ & 23 & 18.9 \\
\hline & Nail discoloration & $8(6.6 \%)$ & $7(5.7 \%)$ & 15 & 12.3 \\
\hline & Skin peeling & $3(2.5 \%)$ & $3(2.5 \%)$ & 6 & 4.9 \\
\hline & Erythema & $5(4.1 \%)$ & $6(4.9 \%)$ & 11 & 9 \\
\hline & Hyper/Hypopigmentation & $10(8.2 \%)$ & $8(6.5 \%)$ & 18 & 14.8 \\
\hline & Swollen face & $6(4.9 \%)$ & $21(17.2 \%)$ & 27 & 22.1 \\
\hline & Sweating & $2(1.6 \%)$ & $17(13.9)$ & 19 & 15.6 \\
\hline
\end{tabular}




\begin{tabular}{|c|c|c|c|c|c|}
\hline \multirow[t]{3}{*}{ Eye disorders } & Eye redness & $3(2.5 \%)$ & $3(2.5 \%)$ & 6 & 4.9 \\
\hline & Eye pain & $1(0.8 \%)$ & $1(0.8 \%)$ & 2 & 1.6 \\
\hline & Foreign body sensation & $0(0 \%)$ & $2(1.6 \%)$ & 2 & 1.6 \\
\hline Fever and Infections & Fever & $21(17.2 \%)$ & $27(22.1 \%)$ & 48 & 39.3 \\
\hline \multirow[t]{2}{*}{ Respiratory } & Cough & $9(7.4 \%)$ & $17(13.9 \%)$ & 26 & 21.3 \\
\hline & Shortness of Breath & $1(0.8 \%)$ & $6(4.9 \%)$ & 7 & 5.5 \\
\hline \multirow[t]{3}{*}{ Nervous Disorders } & Numbness & $5(4.1 \%)$ & $19(15.6 \%)$ & 24 & 19.7 \\
\hline & Tingling sensation & $2(1.6 \%)$ & $2(1.6 \%)$ & 4 & 3.3 \\
\hline & Complete loss of sensation & $4(3.3 \%)$ & $3(2.5 \%)$ & 7 & 5.7 \\
\hline \multirow[t]{4}{*}{ Administration site disorders } & Extravasation & $4(3.3 \%)$ & $4(3.3 \%)$ & 8 & 6.6 \\
\hline & Irritation & $4(4.9 \%)$ & $10(8.2 \%)$ & 16 & 13.1 \\
\hline & Pain & $11(9.0 \%)$ & $19(15.6 \%)$ & 30 & 24.6 \\
\hline & Phlebitis & $0(0 \%)$ & $3(2.5 \%)$ & 3 & 2.5 \\
\hline \multirow[t]{3}{*}{ Urinary } & Urinary tract infections & $6(4.9 \%)$ & $6(4.9 \%)$ & 12 & 9.8 \\
\hline & Frequent urination & $7(5.7 \%)$ & $1(0.8 \%)$ & 8 & 6.6 \\
\hline & Burning micturition & $10(8.2 \%)$ & $4(3.3 \%)$ & 14 & 11.5 \\
\hline Others & Hypocalcaemia & $3(2.5 \%)$ & $5(4.1 \%)$ & 8 & 6.6 \\
\hline
\end{tabular}

\section{Chemotherapy induced neutropenia}

Neutropenia was seen in 38 (31.1\%) patients. Grade I neutropenia was seen in $10.7 \%$ patients followed by Grade II in $7.4 \%$, Grade III in $9.0 \%$ and Grade IV in $4.1 \%$ patients.

\section{Chemotherapy induced thrombocytopenia}

Thrombocytopenia was detected in $28(23 \%)$ patients. Within this group of thrombocytopenic patients, $11.5 \%$ had Grade I, 7.4\% had Grade II, $0.8 \%$ had Grade III and 3.3\% had Grade IV thrombocytopenia.

\section{Prophylaxis during chemotherapy}

Nausea and vomiting are preventable side effects of cancer chemotherapy. Ondansetron alone and Ondansetron in combination with Domperidone were given in $17.2 \%$ and $67.2 \%$ patients respectively for the prevention of cancer chemotherapyinduced nausea and vomiting.

For prevention of medications induced gastrointestinal irritation, pantoprazole: 20 - $40 \mathrm{mg}$, Omeprazole: $20 \mathrm{mg}$ and Rabeprazole: $20 \mathrm{mg}$ was being used. Among these Pantoprazole $40 \mathrm{mg}$ was frequently used accounting for $76.2 \%$ of total prescriptions followed by Omeprazole (9.01\%) and Rabeprazole (3.2\%).

The medication given for the prevention of chemotherapy induced mucositis and stomatitis were povidone-iodine gargle (37.70\%), chlorhexidine (33.61\%), and benzydamine (18.8\%). Besides medications other prophylactic lifestyle modifications such as maintaining good oral hygiene, avoiding spicy food, use of mild-flavored toothpaste were encouraged where appropriate for minimizing oral mucositis.

\section{Assessment of ADRs}

Causality assessment was done for each ADRs by Naranjo's Causality Assessment Scale [6]. It was found that $4 \%$ of the ADRs fell into definite category. 66\% ADRs were in probable category and $30 \%$ ADRs were in possible category. Re-challenge test was positive in definite ADRs.

The severity assessment was done for each ADRs by modified Hartwig and Sigel scale and it was observed that $73.4 \%$ of the ADRs were moderate in severity followed by $20.5 \%$ of mild. Only $6.1 \%$ of the ADRs were severe in nature [7].

Preventability assessment was done for each ADR by Modified Shumock and Thorton scale [8]. The study shows that $42.7 \%$ of the ADRs fell definitely preventable. 52.2\% ADRs were in probably preventable and $5.1 \%$ ADRs were in not preventable.

\section{Action on the suspected drugs}

Figure 1 shows the action taken for the ADRs in the present study. The suspected drug was continued in $36.88 \%$, stopped in $21.3 \%$ dose reduced in $13.9 \%$ and in remaining $27.86 \%$ discontinued and drug was changed.

\section{Outcome of ADRs}

In the study, $44.3 \%$ of ADR cases were completely recovered whereas $24.6 \%$ were in the process of recovery when the data was being taken. ADRs were still continuing in $19.7 \%$ of the cases. Condition of $9.8 \%$ patients was unknown since they were discharged from the hospital. Conditions of $1.6 \%$ patients were fatal (Figure 2). 


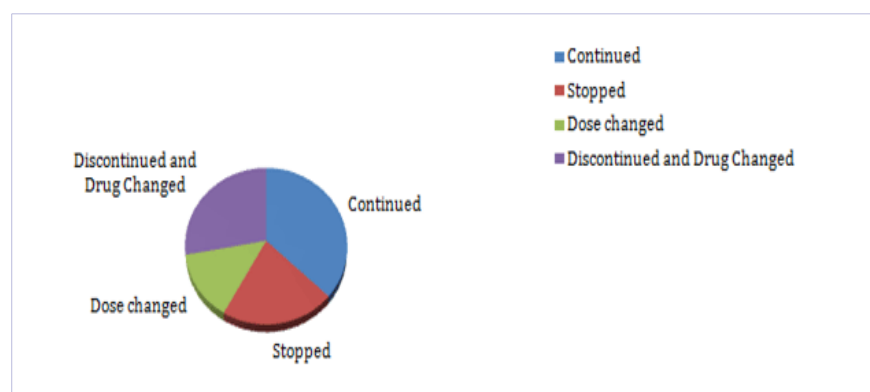

Figure 1: Action on the suspected drugs

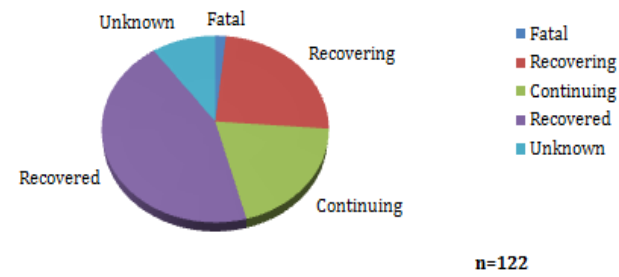

Figure 2: Progress of ADRs

\section{Length of hospital stay}

Length of hospital stays of patients in this study was $2.10 \pm 1.236$ days (Mean \pm S.D). Patients developing ADRs stayed in the hospital for 1-6 days.

\section{Financial burden associated with ADRs due to cancer chemotherapy}

The major cost of ADRs includes hospital cost, clinical investigations and medications (Table 4). Average hospital cost of patients in this study was estimated to be NRs. 1167.21. The laboratories and other cost of patients in this study was NRs 1987.88 and they spent NRs 1196.71 on an average for medications.

\begin{tabular}{|c|c|c|c|c|}
\hline & $\begin{array}{c}\text { Hospital } \\
\text { cost (NRs.) }\end{array}$ & $\begin{array}{c}\text { Clinical } \\
\text { investigations } \\
\text { (NRs.) }\end{array}$ & $\begin{array}{c}\text { Medicine } \\
\text { cost (NRs.) }\end{array}$ & $\begin{array}{c}\text { Blood } \\
\text { transfusions } \\
\text { cost (NRs.) }\end{array}$ \\
\hline Mean & 1167.21 & 1987.8779 & 1196.7131 & 217.21 \\
\hline Median & 1200.00 & 1045.2900 & 1040.0000 & 1000.00 \\
\hline $\begin{array}{c}\text { Std. } \\
\text { Deviation }\end{array}$ & 886.766 & 2210.57553 & 721.09882 & 490.38 \\
\hline Minimum & 0 & 307.00 & 240.00 & 500.00 \\
\hline Maximum & 4200 & 13529.10 & 4310.00 & 2500 \\
\hline Sum & 142400 & 242521.10 & 145999.00 & 26500 \\
\hline
\end{tabular}

\section{Discussion}

In the present study females were found to have more number of ADRs which is similar to another study conducted by Yerramilli, et al. and Podder, et al. [9,10]. This might be attributed to the gender wise differences in drugs pharmacokinetics and pharmacodynamics [11]. Patients aged above 60 years encountered majority of the ADRs. In general the incidence of ADRs is higher in elderly patients as found in other studies [12,13]. Poddar, et al. and Jose et al. have mentioned in their report that incidence of ADRs among elderly and older adults were significantly higher than other age groups [13]. Higher incidence of ADRs in this age group may be due to decline in organ function leading to low metabolizing capacity and reduced excretion resulting in accumulation of drugs in the body and thus increasing the risk of ADRs [14]. Hence, while using chemotherapy in the elderly population additional precautions should be taken. This study also shows that overweight peoples have higher risks for developing cancer than others. Overweight and obesity are now established risk factors for cancer and cancer-related mortality. Obesity has recently been shown to be associated with an increased risk of esophageal adenocarcinoma, thyroid cancer, renal cancer, and multiple myeloma, gallbladder cancer leukemia, pancreatic cancer, non-Hodgkin lymphoma and ovarian cancer [15].

Several types of cancer chemotherapy related ARDs were identified in this study among which bone marrow suppression was the most common. While destroying cancer cells, chemotherapy can also damage rapidly dividing cells of bone marrow resulting in myelosuppression, hence reducing WBCs, platelets and RBCs. Anemia (42.6\%) was the most commonly encountered $\mathrm{ADR}$ as a result of myelosuppression. This finding correlates with the study conducted by Gunaseelan, et al. [16]. Besides anemia $31.1 \%$ patients were found to be neutropenic. Neutropenia resulting from chemotherapy may be life threatening. Neutropenia is the most serious hematologic toxicity of cancer chemotherapy, often limiting the doses of chemotherapy that can be tolerated [17]. Thrombocytopenia was also detected in patients receiving chemotherapy (28\%) that can also lead to potentially life threatening complications, delay in treatment, poorer outcomes, and can consume excessive amounts of health care resources for supportive care [18]. The emergence of Grade III or IV thrombocytopenia in a cancer patient correlates with a significant worsening in the patient's prognosis [19].

Data obtained from Naranjo's Casuality Assessment scale were comparable to the study done by Anju, et al. where they reported that $7 \%$ of the ADRs fell into definite category, $62 \%$ were in probable category and $31 \%$ were in possible category [20]. Severe reactions $(6.1 \%)$ were those which required intensive medical care, can cause permanent harm, or can lead to death. These reactions required advanced treatment procedures and greater financial expenditure. Moderate reactions (73.4\%) did require immediate cessation of the causative drug therapy, substitution with alternative drug and also treatment to the reaction. Mild reactions $(20.5 \%)$ did not require any change in prescribed drugs, 
no extended hospitalization. The figure is similar to the study by Gunaseelan, et al. where they reported that $74.1 \%$ of the ADRs were moderate in severity followed by $17.9 \%$ of mild reactions and $8 \%$ of the severe ADRs [16].

The impact and the management of ADRs is complex. ADRs may enhance costs due to increased hospitalization, prolongation of hospital stay and additional clinical investigations in more severe cases. ADRs may often trigger prescription cascades when new medications are prescribed for conditions that are a consequence of another medication. Aside from these direct costs, there are several indirect costs for patients and their care givers that are incurred by ADRs, such as missed days from work and/or morbidity such as anxiety due to the ADR episode [21].

Hematological adverse effect is one of the most commonly encountered problems resulting from cancer chemotherapy which may be associated with high healthcare costs which results in a substantial economic burden on patients, caregivers and society in general. Frequency and severity of these ADRs should be one of the key factors to be considered while selecting optimal treatment for patients with cancer [22].

In cancer patients, pharmacokinetic parameters can be altered by the disease itself or due to malnutrition, reduced levels of serum-binding proteins, edema, hepatic and/or renal dysfunction. The use of anticancer drugs often results in the use of other agents to reduce or prevent side-effects of the anticancer treatment. Furthermore, cancer itself increases the need for more medications. All of these can increase the risk of clinically significant drug interaction further deteriorating patient's condition. There for it must be the goal of all health care providers to minimize treatment-associated risks as much as possible in these patients.

\section{Conclusion}

Cancer is on the rise, and is known to cause significant impact on the health and socio-economics of a nation. Advancement in modern therapy has changed the way cancer is controlled and has brought significant benefits to the patients. However, ADRs of cancer chemotherapy is common, that can lead to disability and even death. Their prompt recognition, adequate and effective clinical management is mandatory in promoting patients' safety.

\section{Acknowledgements}

We would like to express our hearty gratitude to all the courageous people, who despite of going through agony of cancer, participated with high spirit in this study.

\section{References}

1. Peppas LB, Blanchette JO. Nanoparticle and targeted systems for cancer therapy. Adv Drug Deliv Rev. 2004;56(11):1649-1659.

2. Boyle P, Ferlay J. Cancer incidence and mortality in Europe. Ann Oncol. 2005;16:481-488.

3. Anand P, Kunnumakkara AB, Sundaram C, Harikumar KB, Tharakan ST, Lai OS, et al. Cancer is a preventable disease that requires major lifestyle changes. Pharm Res. 2008;25(9):2097-116.

4. Nerurkar RP, Nadkar MY, Bichile SK. Need for monitoring adverse drug reactions. J Assoc Physicians India. 1998;46:673-674.

5. Smith DL. The effect of patient non- compliance on health care costs. Med Interface. 1993;6:74-84.

6. Naranjo CA, Busto U, Sellers EM, Sandor P, Ruiz I, Roberts EA, et al. A method for estimating the probability of adverse drug reactions. Clin Pharmacol Ther. 1981;30(2):239-45.

7. Hartwig SC, Siegel J, Schneider PJ. Preventability and severity assessment in reporting Adverse Drug Reactions. Am J Hosp Pharm. 1992;49(9):2229-32.

8. Lau PM, Stewart K, Dooley MJ. Comment: hospital admissions resulting from preventable adverse drug reactions. Ann Pharmacother. 2003;37(2):303-4.

9. Kirthi C, Azra Afzal, Mounika Reddy, Syed Aamir Ali, Aparna Yerramilli, Sanjeev Sharma. A study on the adverse effects of anticancer drugs in an oncology center of a tertiary care hospital. Int J Pharm Pharm Sci. 2014;6(2):580-583.

10. Poddar S, Sultana R, Sultana R, Akbor MM, Azad MAK, et al. Pattern of Adverse Drug Reactions Due to Cancer Chemotherapy in Tertiary Care Teaching Hospital in Bangladesh. The Dhaka University Journal of Pharmaceutical Sciences. 2009;8:11-16.

11. Wilson K. Sex-related difference in drug disposition in man. Clin Pharmacokinet. 1984;9(3):189-202.

12. Mallik S, Palaian S, Ojha P, Mishra P. Pattern of adverse drug reactions due to cancer chemotherapy in a tertiary care teaching hospital in Nepal. Pak J Pharm Sci. 2007;20(3):214-8.

13. Jose J, Rao PG. Pattern of adverse drug reactions notified by spontaneous reporting in an Indian tertiary care teaching hospital. Pharmacol Res. 2006;54:226-233.

14. Bates DW, Leape L. Adverse drug reaction. Morreli's Clinical Pharmacology. (4thEdn). McGraw-Hill, Boston, USA. 2000.

15. Van Kruijsdijk RC, Van der Wall E, Visseren FL. Obesity and Cancer: The Role of Dysfunctional Adipose Tissue. Cancer Epidemiol Biomarkers Prev. 2009;18(10):2569-2578. doi: 10.1158/1055-9965

16. Gunaseelan V, Mandal SK, Prasad VN, Khumukcham R, Devi PPV and Singh TT. Adverse drug reactions to cancer chemotherapy in a regional cancer center in Northeast India. Int J Pharm Sci Res. 2014;5(8):33583363.

17. Bodey GP, Buckley M, Sathe YS, Freireich EJ. Quantitative relationships between circulating leukocytes and infection in patients with acute leukemia. Ann Intern Med. 1966;64(2):328-40.

18. Elting LS, Rubenstein EB, Martin CG, Kurtin D, Rodriguez S, Laiho E, et al. Incidence, cost, and outcomes of bleeding and chemotherapy dose modification among solid tumor patients with chemotherapy-induced thrombocytopenia. J Clin Oncol. 2001;19:1137-1146.

19. Schiffer CA, Anderson KC, Bennett CL, Bernstein S, Elting LS, Goldsmith $\mathrm{M}$, et al. Platelet transfusion for patients with cancer: clinical practice guidelines of the American Society of Clinical Oncology. J Clin Oncol. 2001;19(5):1519-1538.

20. Fattinger K, Roos M, Vergères P, Holenstein C, Kind B, Masche U, Stocker DN, et al. Epidemiology of drug exposure and adverse drug reactions in two Swiss departments of internal medicine. Br J Clin Pharmacol. 2000;49(2):158-167.

21. Sultana J, Cutroneo P, Trifirò G. Clinical and economic burden of adverse drug reactions. J Pharmacol Pharmacother. 2013;4(Suppl 1):S73-7.

22. Liou SY, Stephens JM, Carpiuc KT, Feng W, Botteman MF, Hay JW. Economic Burden of Hematological Adverse Effects in Cancer Patients : a systematic review. Clin Drug Investig. 2007;27(6):381-96. 